group for the Eastern Extension Telegraph Company. The first outbreak was in 1902, when I myself was in medical charge. It was very virulent and in spite of all precautions as to sanitation, treatment, moving the site of the coolie lines on two occasions, \&c., 48 cases occurred amongst 60 men, and of these 17 died. At that time many conflicting opinions as to the cause of beri-beri were held by the medical authorities in the Straits Settlements, and those whose opinion seemed to carry the greatest weight did not believe in the rice theory. I therefore discounted it, but was able to come to no conclusion that satisfied me. I thought that an early case had been overlooked when the men were inspected in Singapore and that the others had become infected from this, but in view of recent research and with the dates and history of the epidemic before me I am firmly of the opinion that it was due to the consumption of " uncured" rice. Against my idea of an infection was the fact that no single case occurred amongst the cooks and house servants, and as these had less rice and a more generally generous diet, it is really a distinct point in favour of Dr. Braddon's theory.

Following this epidemic the work was rapidly finished by a large new gang and no more was heard of beri-beri on the island till March, 1908, when the same conditions as before were repeated. New buildings were required and a gang of 68 Chinese coolies left Singapore on Jan. 2nd, taking with them the usual Chinese food-supplies, of which the staple was "uncured" rice. The medical man in charge was Mr. A. H. Macdonald, whose work, during a very trying time, was most excellent and from whom we received long and careful reports. The epidemic began with a case on Feb. 18th followed by another on the 29th. Then six cases developed between March 6th and 30th, and during April it became a scourge, no less than 34 further cases being added. On May 1st three more developed, and of this total of 45,12 died on the island and three others whilst on their way back to Singapore. The whole of the remaining men were taken away from the island on May 2nd and were replaced immediately by a new gang of 29 which arrived on April 28th and whose number was further increased to 45 on July 2 nd. This new gang were housed in new huts and all possible precautions taken, but the only real difference in their work, environment, and diet was that the rice-supply, on my strong recommendation, was changed from the "uncured" to the "cured" variety.

The result is both interesting and instructive. Writing under date June $29 \mathrm{th}, 1908, \mathrm{Mr}$. Macdonald says: "The new gang has been, and still is, in excellent health, not one having been absent from work a single day through illness," and again, under date Sept. 25th, 1908, he states, "The Chinese workmen have had no sickness amongst them beyond minor surgical troubles." Discussing the probable cause of this immunity from beri-beri, he states that he considers the strongest factor is the substitution of "cured " for " uncured" rice, and with this I fully agree. The greater number of this gang of workmen left the island on Oct. 1st, not a single case of beri-beri having occurred amongst them, and I attribute this solely to the fact that a general order has been in force since April, 1908, that no "uncured" rice is to be supplied to the native servants of the company (Chinese or Malay) working on this island.

Reviewing the history of these three epidemics, it seems to me that Dr. Braddon's work marks a great epoch in the study of a disease, the ravages of which must be seen to be believed, and if these details will induce others to put his theories into practice I feel sure they will be gratified with the results.-I am, Sir, yours faithfully,

C. W. CuRTis, M.R.C.S. Eng., \&c., D.P.H.

Principal Medical Officer, Eastern and Associated Telegraph Companies.

Electra House, E.C., June 12th, 1909.

\section{COLOUR VISION IN THE MERCANTILE MARINE.}

To the Editor of THE LANCET.

Sir,-The long time it takes to awaken certain official bodies out of the lethargy into which their official position lulls them is notorious, but it is surely time that the Board of Trade undertook to revise the methods they use for the examination of candidates to whom they grant certificates of proficiency in colour vision when these men have thousands of pounds worth of property and hundreds of lives dependent upon their correct appreciation of coloured lights which are constantly appearing during the night at sea, and who likewise have to read signals made with coloured flags during the daytime. The methods still in vogue are "Gilbertian" to a degree and would scarcely be credited by a stranger unacquainted with certain official methods. This state of affairs was prominently brought forward only a few weeks ago.

It appears that a Mr. - - obtained his certificate as second mate 18 months ago, when he was examined for colour vision by a certain captain in the Mercantile Marine appointed by the Board of Trade for this obviously medical duty, and be was duly passed. After serving for another period at sea he presented himself for examination as "mate," when the same examiner tested his sight and rejected him on account of defective colour vision. Not content with this, the candidate applied for a "special examination," in consequence of which the Board referred him to their special examiners, who consisted of another ship's captain assisted by an assistant professor of physics at the Royal College of Science. These examiners, who, of course, had no knowledge of ophthalmology or physiology, confirmed the previous decision and rejected him. He next on his own initiative applied privately to an ophthalmic surgeon, who found his colour vision so good that it in no way impaired his efficiency as an officer at sea. This, of course, was distinctly awkward for the Board of Trade, who had somehow to get over the difficulty, so in their wisdom they appointed a special tribunal to decide between the doctor and the lay examiners. One would have expected that this tribunal would have been composed of specialists in eyesight, or at any rate of people who knew something of the subject in order to weigh the conflicting evidence. Although such a course would be natural, yet it is not the way of the Board of Trade, who have ideas of their own on such matters, so they appointed the president of the local Marine Board, a stipendiary magistrate, a Member of Parliament, and one or two ship's captains.

Considering that not a single member of this committee had any more knowledge of physiology and sight-testing than had the original examiners, it is obvious that any opinion they might express as to who was right and who was wrong would not be worth the paper on which it was recorded, and an equally satisfactory result would have been arrived at by the simple expedient of tossing $a$ coin and seeing whether it came down heads or tails. Still one must give credit where it is due, and this tribunal not unnaturally came to the conclusion that the doctor was more likely to be right on a medical point than superannuated captains, and so they decided that the candidate had good colour vision, and that his certificate should be granted. Would anyone believe that in the present day such a farce would be gravely carried through by a responsible Government department, and yet this is absolutely what happened about four weeks ago.

In this letter it would be impossible to go into the details of this ridiculous affair, but suffice to say that the important lantern test was used by no one. Holm. gren's wools were, of course, used, and everyone knows how utterly impossible it is to detect all cases of colour-blindness with them. Brilliant spectral lights were employed for an abnormal length of time, and this no doubt produced fatigue, and after-images which would render anyone incapable of correctly naming the colours seen, and as these are pure colours and not impure ones (as is always the case with signal lanterns) so we find those with defective colour sense far more confused by the impure colours than by the pure ones, and thus it is that an examination with spectral lights is by no means a good test to rely on in a routine examination. Colour fatigue is far more readily produced in those whose colour rision is below the normal, but there are scores of people who although not possessing the most highly developed colour sense yet would never mistake a colour used in a signal lantern, and it would be as unfair to reject these as it would be to call a person deaf whose ear was incapable of distinguishing quarter tones in music.

Tbese unhappy candidates are at the present time at the mercy of a board who seem incapable of grasping the fact that an examiner should have some knowledge of the subject on which he is asked to adjudicate. Sxrely there are plenty of ophthalmologists in the land, and if there are, why cannot 
some of them be appointed to examine eyesight? We shall next hear of mining engineers examining candidates in navigation, or sanitary inspectors granting certificates for proficiency in marine engineering. The way in which this particular candidate was tested clearly shows that they were attempting to use some of the methods so long advocated by Dr. Edridge-Green, but that having no knowledge of the subject they utterly failed to grasp his points, and thus we find a man who, but for his perseverance, would have had his livelihood taken away from him, just because of some antiquated regulations to which the Board of Trade still adhere. It is to be hoped that before long this crying injustice both to the candidates and to the general public will be swept away, and that common sense will at last prevail. It is surely no great thing to ask that the Board of Trade shall appoint as their examiners men who know something about their subject.

I am, Sir, yours faithfully,

Harley-street, W., June 7th, 1909. C. DEVEREUX MARshaLL.

\section{A CASE OF SEVERE VERTIGO AND TINNITUS; DESTRUCTION OF THE LABYRINTH; CURE. \\ To the Editor of THE LANCET.}

SIR,-Under the above heading I published in THE LANomT of Sept. 19th, 1908, p. 871, a case which that title sufficiently describes. As a year has now elapsed since the operation, it "may be of interest to your readers to know the further history of the case. I wish also to correct a slight error in the early history of the patient. It is stated in the account given that he had been "free from discharge for over 18 years"; as a matter of fact, the discharge occurred in infancy and ceased before the age of eight years, the patient being 48 years and 6 months old at the time of the operation.

I last saw the patient on May 28th of this year-the first anniversary of his operation. The wound cavity in the left temporal bone was soundly healed and completely epithelialised, the scar of the incision being scarcely visible. The hearing was nil. The patient expressed himself as feel ing "better than he had been for years." He has had no tinnitus and no vertigo whatever since his operation, and is able to carry out his duties as a country clergyman without the least trouble; he is, of course, greatly helped by his proficiency in lip-reading. The condition of his vestibular apparatus was investigated for me very kindly by Dr. Dan McKenzie, the result of his examination being as follows: " Slight nystagmus both, slightly more marked left. Caloric cold, L., spontaneous nystagmus unchanged in 120 secs. No vertigo. Caloric cold, R., (?) increase of spontaneous nystagmus in 90 secs. No vertigo."

Nine days before his operation the hearing in the right ear was : voice, whisper, acoumeter, Galton whistle, bone conduction (to C128), nil. By air conduction he showed perception for $\mathrm{C}^{2}, \mathrm{C}^{3}$, and $\mathrm{C}^{1}$. He perceived the continuous tone series $a^{2}$ to $a^{3}$, but missed $\mathrm{C}_{4}$ sharp. After the operation, the hearing in the right ear improved very slightly, being on June 29th, 1908 : voice 3 inches; Galton whistle, 11048.30 D.V.; bone conduction (C123), 0. By air he showed : $1 \mathrm{C64}$ perception (?), C perception, $\mathrm{C}^{1}-27^{\prime \prime}, \mathrm{C}^{2}-38^{\prime \prime}, \mathrm{C}^{4}-19^{\prime \prime}, \mathrm{C}^{4}-35^{\prime \prime}$, but this increase is now slightly diminished.

I am, Sir, yours faithfully,

MACLEOD YEARSLEY, F.R.C.S. Eng.

Harley-street, W., June 15th, 1909

\section{THE NEW IRISH UNIVERSITIES.}

To the Editor of THE LANCET.

SIr,-In a fortnight the statutes of the new Irish Universities will have passed into law, so that any modifications must be made by Parliament at once. Convocation of the Royal University-largely composed of medical men-has not been consulted about these statutes, and therefore they need amendment. The Convocation recommended the establishment of a degree of B.Sc. in Public Health. This has been done in Dublin but not in Belfast, but instead of being open to graduates of all universities on the Medical Register is confined, apparently, to those who have taken the M. B. in the University at Dublin. It is also complained that an effort is being mac e to shear Convocation of any real strength by confining the power to call meetings of it to the Chancellor or Senate in Dublin, whilst in Belfast a number of members can call a meeting of Convocation. Power to elect a clerk of Convocation has hitherto lain with that body. Now it is transferred to the Senate.

Hitherto Convocation of the Royal University elected a certain proportion-usually of medical men-to the Senate. This power is now taken from them for five years. There is also a strong objection to persons who have been nominated members of the Senate of the new universities being elected to paid professorships or other posts of emolument. If such are elected they should resign from the Senate forthwith. The institution of a degree of D.Sc. in veterinary medicine is desirable; there is a strong Veterinary College in Dublin, but no provision for the study of diseases transmissible from animals to men. Such post-graduate study would be the result of the possibility of obtaining a higher qualification for a veterinary surgeon. In like manner a much-needed stimulus to the study of pharmacology would result from the granting of a B.Sc. degree in pharmacology for registered pharmacists. I am, Sir, yours faithfully,

\section{Dublin, June 13th, $1909 . \quad$ J. C. MCW ALTER, M.A. R.U.I.,}

PS.-Unless power is given to the statutes to confer these new degrees Convocation will be unable to do so afterwards.

\section{CEREBRAL HÆMORRHAGE AND HYPER- PYREXIA.}

To the Editor of THE LANCET.

SiR,-In THE Lancet of June 12th, p. 1716, you published a letter from Dr. Morgan Richards relating to a case of cerebral hæmorrhage followed by hyperpyrexia and death, which occurred on board the Pacific Company's R.M.S. Oropesa. By a strange coincidence $\mathrm{I}$ had a similar experience, curiously enough on the same boat and in practically the same part of the Atlantic. A passenger, aged 35 years, who previously to his death looked to all intents and purposes a healthy man, was one morning " seized with a fit" when about three days' journey from St. Vincent. The heat had been very trying and when I saw him he was in the usual condition seen in cerebral hæmorrhage, cyanosis, stertor, coma, \&c. When examining him I was struck with the extraordinary heat given out by the body, and on taking the temperature in the axilla I found it $110^{\circ} \mathrm{F}$.; in fact, the mercury had gone right up to the end of the thermometer. On procuring another instrument graduated to $115^{\circ}$ I found the temperature in the axilla was $111^{\circ}$ and in the rectum $111.5 \circ$. The patient died four hours after the seizure. Hyperpyrexia before death is quite a common accompaniment of cases of cerebral hæmorrhages and in injuries to the head, and in reply to your correspondent, Mr. V. P. Norman, this phenomenon seems to me to be a clinical fact quite often recorded. I am, Sir, yours faithfully,

Victoria Hospital, Folkestone, June 14th, 1909

B. H. Palmer, M.B., B.C. Cantab.

\section{BLOOD EXAMINATION IN SUSPECTED APPENDICITIS.}

Io the Editor of THE LANCET.

SIR, - In the interesting case of appendicitis reported by Dr. J. S. Boden and Mr. E. M. Corner in THE LANCET of June 12th, p. 1682, it seems to me that had a blood count been made on the same day (Jan. 28th) as the blood specimen showed a negative typhoid reaction a diagnosis of suppuration could have been made. On the 26 th the blood count would probably have indicated the presence of pus, and $I$ am inclined to think that a leucocytosis would have been found cn the 23 rd or possibly even on the 22nd. It is evident that very little would have turned the balance in favour of early operation, and an increased white cell count, so rarely found in typhoid fever, would have been sufficient. One has not to wait for a large abscess before getting the blood change-a single drop of pus is sufficient, as was found in a case $I$ operated on lately where the white cells numbered 35,000 per cubic millimetre and where the ovaries and tubes were much swollen and adherent, and a single drop of pus was 